\title{
Left main stem coronary artery disease
}

\section{Retrospective review of 26 patients treated surgically or medically}

\author{
L. J. D A Y, H. O. VALLIN ${ }^{1}$, a nd E. SOW T ON \\ Cardiac Department, Guy's Hospital, London SE1
}

\begin{abstract}
Day, L. J., Vallin, H. O., and Sowton, E. (1976). Thorax, 31, 522-526. Left main stem coronary artery disease. Retrospective review of 26 patients treated surgically or medically. The clinical, angiographic, exercise testing, operative, and follow-up data of 26 patients found at angiography to have left main stem coronary artery stenosis, defined as a reduction in the lumen diameter of $50 \%$ or more, are reviewed. There was a high incidence of significant proximal stenosis in the branches of the left main stem. No clinical features were found to distinguish patients with left main stem stenosis.

All patients were considered for saphenous vein bypass grafting, selection being based upon the severity of symptoms, left ventricular function, and suitability of the coronary vessels for grafting. 'Two patients died within 24 hours of coronary angiography.

Nine patients were operated on with no mortality. There has been one late cardiac death during a mean follow-up time of 13 months. All patients were symptomatically improved with a significant $(\mathrm{P}<0.01)$ increase in exercise ability postoperatively.

Fifteen patients were not operated on. Six of these patients were regarded as operable but surgery was deferred; five have died at a mean time of 722 months. Five of the nine patients regarded as inoperable have died at a mean follow-up time of 14.8 months. The five non-surgical survivors remain symptomatic with no significant change in exercise ability.

Recently reported surgical and medical series of patients with left main stem stenosis are reviewed.
\end{abstract}

Significant left main stem disease usually occurs in combination with major stenoses elsewhere in the coronary circulation and has been reported to have a poor prognosis (Webster, Moberg, and Rincon, 1974; Burggraf and Parker, 1975). Good results in some surgical series suggest that saphenous vein bypass grafting may be the preferred method of treatment (Lavine et al., 1972; Zeft et al., 1974; Balcon, Banim, and Donaldson, 1975).

In this paper we report our experience with 26 patients who had $50 \%$ or greater stenosis of the left main stem coronary artery.

\section{METHODS}

The clinical records and angiographic findings in 454 patients seen since 1971 who had coronary artery disease were reviewed. Information was obtained regarding length of history of angina,

\footnotetext{
${ }^{1}$ Present address: Serafimerlasarettet, F-11283,'Stockholm, Sweden
}

clinical status before presentation, and physica examination at admission. Angina was classifie $\Phi$ according to severity (Balcon et al., 1970) (gradè 1 -angina with greater than normal exertion grade 2-pain with normal exertion such as walk ing briskly; grade 3-pain with less than normaP exertion; grade 4-angina at rest). Unstable angina was defined as progressive angina with. severe episodes, some of which occurred at reș and were only partially relieved by or totally unf responsive to trinitrin. The incidence of previous myocardial infarction was assessed by reviewing electrocardiograms according to the usual criteria (Hurst et al., 1974). Cardiomegaly was defined as a cardiothoracic ratio of more than $50 \%$ on the chest radiograph.

Left ventriculography and selective coronar $\bar{b}$ angiography was performed in all patients. Lef ventricular end-diastolic pressure, post $\mathrm{A}$ wave was measured before any contrast mediun was injected. Left ventriculograms were classified? 
Class 0 normal function

Class 1 minor general reduction of function

Class 2 hypokinetic, akinetic or aneurysmal area

Class 3 moderate general reduction of function with or without class 2

Class 4 grossly reduced function with or without class 2.

Left main stem stenoses were classified as $50-70 \%$ or greater than $70 \%$ reduction in diameter of the vessel lumen. Significant additional vessel involvement was said to have occurred if the left anterior descending artery, the circumflex artery or the right coronary artery had a stenosis of $70 \%$ or more.

Exercise tests were carried out in the sitting position on either the Elema-Schonander or Monark exercise bicycles (Roy, Day, and Sowton, 1975).

A perioperative myocardial infarction was regarded as having occurred if in comparison with the tracing before surgery there were pathological $Q$ waves in two or more leads or loss of $R$ voltage in two or more of the chest leads.

Recent information was obtained when 11 of the 13 living patients were reviewed and a full history, examination, ECG, chest radiograph, and exercise test were performed. Follow-up data from the other two were obtained from their physicians. Functional classification was according to the New York Heart Association.

Each patient was considered for saphenous vein bypass grafting of the coronary arteries, and selection for operation was based upon severity of symptoms, adequacy of left ventricular function, and suitability of vessels for grafting.

\section{RESULTS (Table I)}

Twenty-six patients were found to have significant left main stem stenosis, all male, giving an inci- dence of $5.7 \%$ in the 454 coronary angiograms reviewed. Two patients died within 24 hours of coronary angiography and are considered separately; nine patients underwent aortocoronary saphenous vein bypass grafting and 15 patients were not operated on.

ANGIOGRAPHIC FINDINGS (Table II) Only one patient was found to have a normal ventricle. Fourteen were found to have either a class 3 or 4 ventricle, 12 of whom were in the non-surgical group.

Sixteen patients had greater than $70 \%$ stenosis of the left main stem coronary artery. An isolated left main stem stenosis was not found. There was an average of 2.2 vessels involved per patient in addition to the left main stem stenosis.

ANGIOGRAPHY-RELATED MORTALITY (Table I) Two patients died within 24 hours of coronary angiography. Both patients were severely incapacitated by angina and one was in cardiac failure with a past history of myocardial infarction.

The first patient had a class 4 ventricle. There was significant involvement of all the coronary arteries and a $70 \%$ stenosis of the left main stem. Six hours after investigation he became unconscious and died. At necropsy major cerebral emboli were shown to have originated from the left ventricle in which there was an aneurysm containing thrombus.

The second patient had an unsatisfactory ventriculogram that could not be assessed. There was significant involvement of all the coronary arteries and a $50 \%$ stenosis of the left main stem. During angiography there was an episode of ventricular fibrillation which was successfully treated. He died the next day after an episode of chest pain. At necropsy a recent thrombosis of the left anterior descending artery was found.

T A B L E I

PATIENT DATA

\begin{tabular}{|c|c|c|c|c|c|}
\hline & \multirow{2}{*}{ Total Group } & \multirow{2}{*}{ Surgical } & \multicolumn{2}{|c|}{ Non-Surgical } & \multirow{2}{*}{$\begin{array}{c}\text { Angiographic } \\
\text { Deaths }\end{array}$} \\
\hline & & & Operable & Inoperable & \\
\hline $\begin{array}{l}\text { Number of patients } \\
\text { Age (years) } \\
\text { Duration of angina (months) } \\
\text { Angina: Grade } 1 \\
\text { Grade } 2 \\
\text { Grade } 3 \\
\text { Grade } 4 \\
\text { Unstable angina } \\
\text { Recent exacerbation of angina } \\
\text { Previous infarction } \\
\text { Cardiomegaly } \\
\text { Cardiac failure }\end{array}$ & $\begin{array}{l}26 \\
51 \cdot 1 \\
49 \cdot 5 \\
0 \\
6 \\
12 \\
3 \\
5 \\
16 \\
12 \\
7 \\
3\end{array}$ & $\begin{array}{l}9 \\
48 \\
43 \cdot 8 \\
0 \\
0 \\
6 \\
1 \\
2 \\
7 \\
3 \\
1 \\
1\end{array}$ & $\begin{array}{l}6 \\
54 \cdot 2 \\
37 \cdot 6 \\
0 \\
3 \\
2 \\
0 \\
1 \\
4 \\
4 \\
2 \\
0\end{array}$ & $\begin{array}{l}9 \\
52 \cdot 1 \\
54 \cdot 6 \\
0 \\
3 \\
3 \\
1 \\
2 \\
4 \\
4 \\
3 \\
1\end{array}$ & $\begin{array}{l}2 \\
50 \cdot 1 \\
62 \\
0 \\
0 \\
1 \\
1 \\
0 \\
1 \\
1 \\
1 \\
1\end{array}$ \\
\hline
\end{tabular}


T A B L E I I

ANGIOGRAPHIC FINDINGS ${ }^{\wedge}$

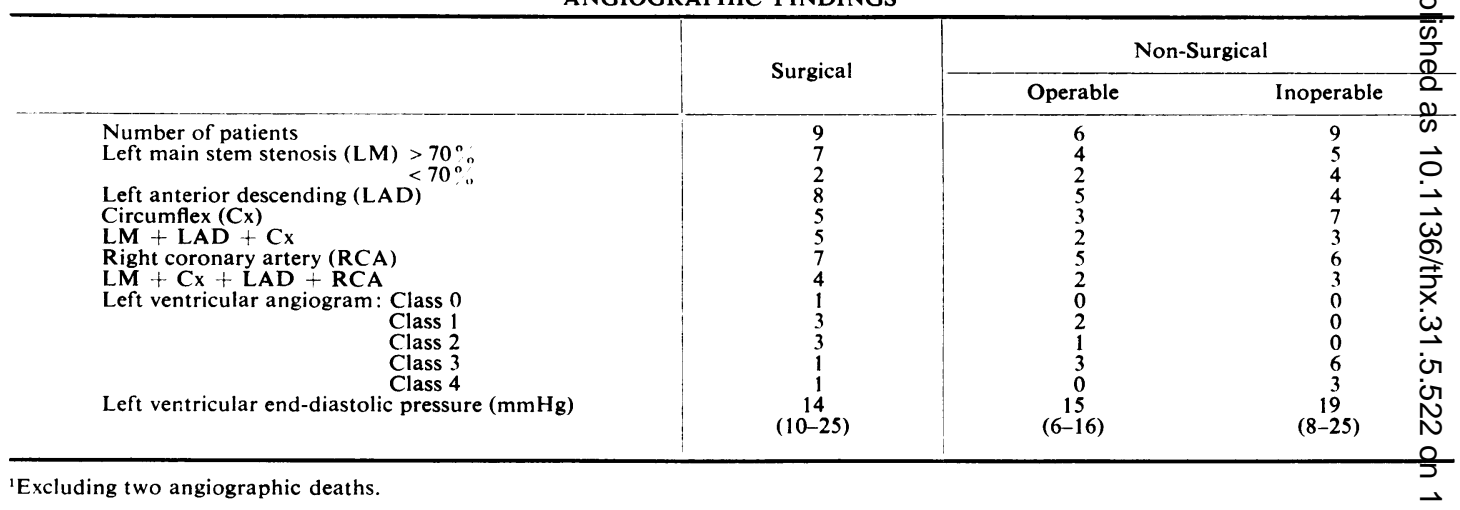

SURGICAL, GROUP (Table III) Nine patients underwent aortocoronary saphenous vein bypass grafting. There were no operative deaths. One patient had a perioperative myocardial infarction $(11 \%)$. One patient with a class 4 ventricle has died six months after surgery in congestive cardiac failure. There have been no late myocardial infarctions. All surviving patients are symptomatically improved and four are completely free of angina.

Seven patients had exercise testing performed both before and after surgery. In the initial test a mean total work of $1518 \mathrm{kpm}$ was performed. Six patients were stopped by angina and one by fatigue. All showed ST segment depression which exceeded $2 \mathrm{~mm}$ in three patients.

After surgery all patients did more work and the mean total work performed was $3102 \mathrm{kpm}$. One patient was stopped by angina, three by dyspnoea, and three by fatigue. Two patients showed ST depression of 1.5 and $2 \mathrm{~mm}$ respectively. The difference in work performed by the group was significant $(\mathrm{P}<0 \cdot 01)$.
NON-SURGICAI. GROUP (Table III) Of the d5 patients in this group, nine were regarded cas inoperable. Five of these nine have died from cardiac causes at a mean time of 14.8 (range 3-26) months.

Six patients were regarded as operable, Git surgery was deferred because of symptomanic improvement in four and because of the intent $\bar{n}$ n to investigate symptomatic peripheral vascu传r disease in two. Five of these patients have dR्र from cardiac causes at a mean follow-up time $\underset{0}{ }$ f $7 \cdot 2$ (range 6-10) months.

There has been no significant symptomatic 蛋provement in the survivors. All are taking anjianginal medication, and two are taking digos and diuretics in addition.

Four of the five surviving patients have had exercise tests, achieving a mean total work at the most recent test of $2071 \mathrm{kpm}$, which was ณot significantly different from the test performed $\xi_{a}$ the time of coronary angiography. 


\section{DISCUSSION}

In considering left main stem coronary artery stenosis, a reduction in lumen diameter of $50 \%$ or more was regarded as significant. Although flow at rest remains relatively unaffected by a stenosis of less than $70 \%$, blood flow is restricted by lesser degrees of obstruction when demand increases (Logan, 1975; Newman, Walesby, and Bowden, 1975). Distal flow in patients with left main stem stenosis is further reduced by the frequent occurrence of severe proximal stenosis in the left anterior descending and circumflex branches. When these stenoses in series are critical the net effect on flow is additive (Gould and Lipscomb, 1974). In this report 23 patients had significant proximal stenoses of these arteries, and other reports have noted similar incidences (Cohen et al., 1972; Lavine et al., 1972; Zeft et al., 1974).

In reported results of 280 patients with left main stem stenosis treated surgically by saphenous vein bypass grafting there was a $13.5 \%$ surgical mortality (range 4-29\%) (Cohen et al., 1972; Lavine et al., 1972; Harrell et al., 1974; Khaja et al., 1974; Talano et al., 1974; Zeft et al., 1974; Balcon et al., 1975; DeMots et al., 1975). The late mortality was $5.1 \%$ at an average time of 20.5 months, and the survivors were reported as having symptomatic improvement.

In reports of medically treated groups with left main stem stenoses followed for up to six years there has been a yearly mortality ranging between 10.9 and $17 \%$ (Bruschke, Proudfit, and Sones, 1973; Webster et al., 1974; Burggraf and Parker, 1975). In a recent report of 141 patients followed up for a minimum of five years, Lim, Proudfit, and Sones (1975) found a five-year mortality of $51 \%$. There is no long-term randomized study available to compare medical and surgical treatment of patients with left main stem stenosis. However, DeMots et al. (1975) have found in a comparable but non-randomized group that the survival of the surgical group between 15 and 36 months was better but did not reach statistical significance.

Our own finding that five out of six patients in whom surgery was deferred died after an average of seven months gives a mortality of $83 \%$ which is greater than would be expected from the reports of medically treated patients reviewed above. However, Talano et al. (1974) and DeMots et al. (1975) have also found a high mortality in medically treated patients in the first year after investigation. Four of our five medically treated operable patients who died presented with a recent exacerbation of angina, and we now believe that this clinical feature indicates the need for early operation.

In contrast to the medically treated patients, the surgical patients in this series have a low late mortality and there has been a significant symptomatic improvement. The progress of the surgical patients suggests that this is the method of choice for patients with left main stem stenosis provided left ventricular function is adequate.

In assessing the suitability of the left ventricle for saphenous vein bypass grafting, patients with class 4 ventricles were generally regarded as inoperable. The one patient with a class 4 ventricle operated upon was improved by surgery initially but died after six months in cardiac failure. The left ventricular end-diastolic pressure was found to span a wide range, and the mean value was comparable in both our operated and non-operated groups. We feel it is not a useful guide to selection for surgery in the individual patients.

No clinical features were found which would allow patients with left main stem stenosis to be distinguished from other groups with severe coronary artery disease, and this confirms similar conclusions by others (Harrell et al., 1974). Khaja et al. (1974) found that $82 \%$ of his patients with left main stem stenosis presented with the clinical picture of unstable angina. Although 16 of the patients in this report presented with an exacerbation of angina, only five had unstable angina. During the period covered by this review 46 patients presented with unstable angina, only five of whom $(19 \%)$ were found to have a left main stem stenosis.

Cohen et al. (1972) reported $2 \mathrm{~mm}$ or more ST depression on exercise testing in $82 \%$ of their patients with left main stem stenosis and considered this a useful guide in distinguishing patients with either left main stem disease or proximal stenosis of all three major coronary vessels. However, we found only $42 \%$ of the patients exercised had ST depression of $2 \mathrm{~mm}$ or more.

The two patients who died in relation to coronary arteriography, an incidence of $8.2 \%$, were both studied by the Judkins technique although this was not apparently implicated.

A similar mortality at investigation in patients with left main stem stenosis has been noted by other authors (Cohen et al., 1972; Lavine et al., 
1972), emphasizing the risks of coronary angiography in these patients. We feel these risks are related to the extent of additional disease rather than the presence of the left main stem obstruction itself.

\section{CONCLUSIONS}

Our conclusions are:

1. Patients with left main stem stenosis cannot be distinguished clinically.

2. Surgical treatment of patients with acceptable left ventricular function can be carried out with a low mortality both operative and late. This treatment results in symptomatic relief and improved exercise tolerance.

3. There is a high mortality during the first year after investigation among patients suitable for surgery but in whom the operation is delayed.

4. Exacerbation of angina is a serious prognostic sign, and surgery should be carried out urgently before infarction occurs.

We thank Dr. D. Deuchar for allowing us access to his patients, Mr. D. Ross and Mr. A. Yates who operated on these patients for allowing us to review the operative reports, and Dr. J. Dow in whose department these patients were investigated. Our thanks are also due to Mrs. G. Lcckton who helped to perform the exercise tests.

\section{REFERENCES}

Balcon, R., Banim, S. O., and Donaldson, R. M. (1975). Experience with left main stem coronary artery stenosis (Abstract). British Heart Journal, 37, 551 .

Balcon, R., Leaver, D., Ross, D., Ross, K., and Sowton, E. (1970). Clinical evaluation of internal mammary-artery implantation. Lancet, 1, 440.

Bruschke, A. V. G., Proudfit, W. L., and Sones, F. M., Jr. (1973). Progress study of 590 consecutive nonsurgical cases of coronary disease followed 5-9 years: I. Arterographic correlations. Circulation, 47, 1147.

Burggraf, G. W. and Parker, J. O. (1975). Prognosis in coronary artery disease. Angiographic, hemodynamic, and clinical factors. Circulation, 51, 146.

Cohen, M. V., Cohn, P. F., Herman, M. V., and Gorlin, R. (1972). Diagnosis and prognosis of main left coronary artery obstruction. Circulation, 45-46. Supplement 1, 57.

DeMots, H., Bonchek, L. I., Rösch, J., Anderson, R. P., Starr, A. and Rahimtoola, S. H. (1975). Left main coronary artery disease: risks of angiography, importance of coexisting diseasegf other coronary arteries and effects of revescularization. American Journal of Cardiolo 36, 136.

Gould, K. L. and Lipscomb, K. (1974). Effects of coronary stenoses on coronary flow reserve thd resistance. American Journal of Cardiology, 34, 48.

Harrell, R. R., Oberman, A., Russell, R. $\overrightarrow{\vec{\phi}}$., Kouchoukos, N. T., Holt, J. H., and Rack: C. E. (1974). Left main coronary disease: predictability and survival in medical versus surgikal groups. Circulation, 49-50, Supplement 3, 35.

Hurst, J. W., Logue, R. B., Schlant, R. C., änd Wenger, N. K., Eds. (1974). The Heart, ind edition, Ch. 5i, p. 1039. McGraw-Hill, Now York.

Khaja, F. U., Sharma, S. D., Easley, R. M., Ir. Heinle, R. A., and Goldstein, S. (1974). Left main coronary artery lesions: risks of catheterization; exercise testing and surgery. Circulation, 49-50, Supplement 2, 136.

Lavine, P., Kimbiris, D., Segal, B. L., and Linhart, J. W. '(1972). Left main coronary artery disease: clinical, arteriographic and hemodynamic $9 \mathrm{p}-$ praisal. American Journal of Cardiology, 30, $7 \ddot{y}$.

Lim, J. S., Proudfit, W. L., and Sones, F. M., 9r. (1975). Left main coronary arterial obstruction: long-term follow-up of 141 nonsurgical cases. American Journal of Cardiology, 36, 131.

Logan, S. E. (1975). On the fluid mechanics ${ }_{\infty}^{\circ}$ human coronary artery stenosis. ILEE Tratsactions on Biomedical Engineering, 22, 327.

Newman, D. L., Walesby, R. K., and Bowden, N. L. R. (1975). Hemodynamic effects of ac gite experimental aortic coarctation in the dog. Circulation Research, 36, 165.

Roy, P., Day, L., and Sowton, E. (1975). Effect Of $_{\text {of }}$ new $\beta$-adrenergic blocking agent, Atenotol (Tenormin), on pain frequency, trinitrin consumption, and exercise ability. British Med Journal, 3, 195.

Talano, J. V., Scanlon, P. J., Khan, M., Meado円s, W. R., Loeb, H. S., Pifarré, R., and Gunnar, R. M. (1974). Influence of surgery on survivabin 145 patients with left main coronary disease. Circulation, 49-50, Supplement 3, 110.

Webster, J. S., Moberg, C., and Rincon, G. (19 $\overline{\overline{\mathrm{k}}}$ ). Natural history of severe proximal coronary artery disease as documented by coronay cineangiography. American Journal of Cargiology, 33, 195.

Zeft, H. J., Manley, J. C., Huston, J. H., Tea $\mathrm{r}$, A. J., Auer, J. E., and Johnson, W. D. (19飞at). Left main coronary artery stenosis: results coronary bypass surgery. Circulation, 49, 68 . 욤

Requests for reprints to: Dr. E. Sowton, Cargac Department, Guy's Hospital, London SE1. 